\title{
Assessment of patient satisfaction of certified and non-certified private dental clinics in Athens
}

\author{
Evangelia Zampa*1 $^{* 1}$ Spyridon Silvestros ${ }^{2}$, Vasiliki Kapaki ${ }^{3}$, Kyriakos Souliotis ${ }^{3}$ \\ ${ }^{1}$ School of Medicine, National and Kapodistrian University of Athens, Athens, Greece \\ ${ }^{2}$ Department of Dentistry, National and Kapodistrian University of Athens, Athens, Greece \\ ${ }^{3}$ Department of Health Policy, University of Peloponnese, Peloponnese, Greece
}

Received: September 17, 2019

Accepted: January 15, 2020

Online Published: February 24, 2020

DOI: $10.5430 /$ ijh.v6n1p35

URL: https://doi.org/10.5430/ijh.v6n1p35

\begin{abstract}
Background: In recent years, the issue of quality assurance in health services has emerged in the forefront, with strong research and practical interest. In addition, there is a number of changes to health service users who nowadays have higher expectations of satisfaction, efficiency and quality of health services.

Aim: The aim of the present study is to assess the satisfaction of patients and, by extension, the quality of the services provided both in certified and non-certified private dental practices in Athens, to highlight the difference in the services provided and the areas in which it appears.

Methods: This is a quantitative study of dental patients' satisfaction in Athens using an anonymous and self-completed questionnaire. The aggregate sample collected is 317 patients within three months of the questionnaire being shared. In particular, the sample for certified dental places was 176 patients, while the sample of non-certified dental places was 141 patients. For the statistical analysis, the SPSS program for Windows version 25 was used, and the tables were created with Microsoft Excel 2010 based on the SPSS analysis data.

Results: The results showed differences between the social level of patients, the permanent residence of the participants as well as differences in the reason for choice and visit to each dental place, while on the questions about the satisfaction of the services the differences were little. The questions with the most shared responses were those in the financial basis. Correlation coefficients did not show any statistically significant relationship between demographic characteristics and satisfaction, with the exception of the level of education of patients in certified dental clinics.

Conclusions: Although the results of the research showed little differences in the satisfaction of the patients between certified and non-certified dental clinics, these results are quite limited due to the small number of certified dental clinics in Greece. Further research is needed to produce safer conclusions.
\end{abstract}

Key Words: Dental care services, Quality of health services, Patients'satisfaction, Health services' certification

\section{INTRODUCTION}

Oral health is an important factor in the general health of the individual. Modern scientific approach treats oral health not only as the health of teeth and gums but as the absence of chronic oral pain, oral cavity and pharyngeal cancer, congenital anomalies and any other disease or disorder affecting the craniofacial complex. ${ }^{[1]}$

\footnotetext{
*Correspondence: Evangelia Zampa; Email: elina_zampa@windowslive.com; Address: School of Medicine, National and Kapodistrian University of Athens, Mikras Asias str., Athens, Greece. 
The factors affecting oral health are prevention and control of oral health, continuous oral care, the frequency of visits to the dentist, the profile of the dentist, lifestyle and habits, quality of life, the cost of dental care and other socio-demographic factors such as gender, age, educational level, occupation, income class and insurance coverage. ${ }^{[2]}$

Every health system is a production process, the product of which is the means to prevent disease, rehabilitate, improve and maintain the well-being of every individual, so it is of great importance. ${ }^{[3]}$ Nowadays, the concept of the quality of consumer products and services has grown by defining consumer and business behavior. Respectively, it acquires a great deal of importance also for health services, which have as their primary objective the satisfaction of the vital needs of every person. ${ }^{[4]}$

The necessity for objectively documented quality at international level is now also touching dental services, due to the strengthening of global competitiveness. The first person who tried to define quality in healthcare was Avedis Donabedian in 1980 who stated that quality is to maximize patient satisfaction, taking into account the profits and losses in the care process. ${ }^{[5]}$ He added that assessing the quality of health care delivery should be done not only for the performance of health professionals but also for patients.

Quality in health care services is a multidimensional concept that is constantly changing and adapting. The main factors that determine the quality of dental care services are the following: ${ }^{[6-9]}$

- The skills, knowledge, experience and professional conscience of service providers. High level of dentistry is the most important prerequisite for early diagnosis and effective treatment of any oral health problem.

- The behavior of staff towards patients. Friendship, kindness and respect for the patient's human dignity are a universal requirement in the modern age.

- The readiness of dental care.

- The patient's access to dental care without bureaucracy, intermediaries and waiting and with the greatest freedom of choice.

- Speed in solving the problem of patients' oral health.

- Correctness in treatment choice.

- Post-service support, starting with detailed instructions and ending with the existence of an accurate record and an organized patient re-examination system.

- The use of new technology.

- The cost.

In order to specify these factors, the International Organization for Standardization has developed the ISO 9001 stan- dard, most recently revised in 2015. In addition, DIN EN 15224 has been developed, which is the European framework for specifications for the development and implementation of management systems specific to health services which combines the benefits of ISO 9001:2015 with quality requirements for health services. Its latest revision was made in 2016. ${ }^{[10]}$ Based on these standards, many international organizations have been created in order to certificate healthcare services. Some of the most important are The Joint Commission, International Society for Quality in Health Care, Australian Council on Healthcare Standards, TEMOS International Healthcare, TÜV Thüringen and Swiss Approval International. Consequently, a certified dental clinic has been evaluated on all the aforementioned quality features and this is the key point that distinguish it from a non-certified clinic.

A more general approach links the quality of health services to patient satisfaction. ${ }^{[11]}$ Patients, expressing their views on the services they experienced, assess the quality of health care they received according to the degree of coverage of their expectations. ${ }^{[12]}$ Thus, integrating the measurement of patient satisfaction into a quality assurance program improves the organization's climate, employee morale and helps to recognize the efforts made to meet the needs of patients.

The aim of the present study is to assess the satisfaction of patients and, by extension, the quality of the services provided both in certified and non-certified private dental practices in Athens, to highlight the difference in the services provided and the areas in which it appears.

\section{METhOD}

A questionnaire was given in every patient after informing about the aims of the research and about the anonymity of answers. A total of 317 patients consented and filled the questionnaire within three months of their availability. More specifically, the sample for certified dental clinics consisted of 171 patients coming to certified private dental clinics and 146 patients coming to non-certified private dental clinics. For the sample of the non-certified clinics were selected only clinics specialized in a field of dentistry and not general dentists, since certified clinics are comprised of specialized dentists of various specialties, so the comparison would be more direct. The patient filled the questionnaire by himself, put it in a sealed white envelope and then in a box with all the others questionnaires.

Each patient was self-administered a 31-items questionnaire adapted from that of the University of Adelaide consisting of questions relating to the satisfaction of medical and paramedical staff, environment, access, costs and efficiency. ${ }^{[13]}$ Each item was assessed on a 5-item Likert-type scale (1- Strongly 
disagree to 5- Strongly agree). The use of this questionnaire has been licensed by its developers. In addition, the first part of the questionnaire refers to the demographic features of each patient. This part was constructed after studying the literature and was added in order to better analyze the results of this quantitative research.

The Statistical Program for Social Sciences (SPSS) for Windows version 25 was used to conduct most data analysis, while Microsoft Excel 2010 was used to produce the tables from data supplied by SPSS analysis.

There were no ethical risks in this study. The information collected was confidential, the data was encoded and at no point questions could under any circumstances lead to the identification of the respondent.

\section{Results}

A total of 141 patients consented and filled the questionnaire from non-certified dental clinics and the majority was female $(56 \%)$. Most were 41-60 years old (48\%), the least were $<25$ years old (7\%). The majority was from Greece (99\%), leaving in Athens (89\%), they have a bachelor's degree $(50 \%)$ and they are employed $(63 \%)$. Their personal monthly income is $1001-1500$ euros (31\%) and it's not their first time in the dental clinic (93\%). The main reason of their visit was total mouth rehabilitation (44\%) and the main reason of their choice was dentist's specialization e.g., periodontics, prosthodontics, endodontics etc. (41\%). About the time interval between phone and the appointment that was $5.86 \pm$ 4.36 days and the waiting time was $10.83 \pm 9.94$ minutes mainly on the night shift $(67 \%)$. Finally, the majority of patients answered that their health status is very good $(43 \%)$.

On the contrary, a total of 176 patients consented and filled the questionnaire from certified dental clinics and the majority was male $(51 \%)$. Most were 41-60 years old (47\%), the least were $<25$ years old $(6 \%)$. The majority was from Greece (97\%), leaving in Athens (80\%), they have a bachelor's degree (46\%) and they are employed $(77 \%)$. Their personal monthly income is $>2001$ euros $(25 \%)$ and it's not their first time in the dental clinic $(91 \%)$. The main reason of their visit was recall maintenance $(49 \%)$ and the main reason of their choice was certification (48\%). About the time interval between phone and the appointment that was $3.89 \pm 2.98$ days and the waiting time was $16.6 \pm 10.94$ minutes mainly on the night shift $(86 \%)$. Finally, the majority of patients answered that their health status is good (48\%).

As regards to questions of services' satisfaction the differences were less. These included a greater difficulty in making an appointment on the certified areas, the fact that patients in certified dental clinics did not see the same dentist or the one they would like to see each time and that the completion Published by Sciedu Press of their treatment plans in those dental practices was more time-consuming. The questions about the financial part had the most shared answers. Table 1 shows in detail the answers in each item and the proportions of each category.

In order to produce even more tangible results, we proceeded with the analysis of the correlation of the independent variables (demographic questions) with the dependent variables (key questions from the second part of the questionnaire) using the Spearman correlation coefficient $(\rho)$.

Regarding non-certified dental surgeries, it appears that no relation of variables seems to have a moderate or strong correlation. The most positive correlation was between the reason for choosing the dentist and whether the patient was satisfied with the dental care he received. Instead, age correlates with the convenience of the route.

Regarding certified dental clinics, and in this case there are no pairs of variables with moderate or strong correlation. The greatest positive correlation was between the level of education of the patient and how satisfied he was with the dental care he received. On the contrary, the biggest negative correlation was between the patient's state of health and whether the treatment was time-consuming.

\section{Discussion}

A literature search was performed in MEDLINE using the PubMed database of the US National Library of Medicine and this is the first research paper which tried not only to evaluate the patients' satisfaction coming to certified and non-certified private dental clinics, but also to indicate where differences are identified. The published papers only refer to non-certified areas and most of them have taken part in university or hospital institutions rather than in private clinical practice, so the comparison is not straightforward since the conditions of the research differ from the present.

Concerning the demographic features of the participants, differences were found between the two categories. More specifically, there was an increased proportion of patients from rural areas in certified dental clinics indicating that patients prefer to make a long journey in order to receive dental care services from the specific clinics. An additional difference was the better social level of patients who chose the certified clinics according to their educational level, where the holders of postgraduate and doctorate degrees were much more, and their financial situation since the majority declared monthly individual income $>2001$ euros. Correlation coefficients did not show any statistically significant relationship between income and satisfaction, as opposed to the work of Lee et al. where the results showed that as the patient's income increases, both expectations increase and satisfaction is diminished. ${ }^{[14]}$ 
Table 1. Questionnaire analysis in both categories of dental clinics

\begin{tabular}{|c|c|c|}
\hline Items & Non-certified (mean \pm SD) & Certified (mean \pm SD) \\
\hline 1. The distance made it difficult to attend my last visit. & $1.5 \pm 1.039$ & $1.69 \pm 1.179$ \\
\hline 2. Travel to the dental clinic was convenient. & $4.18 \pm 1.249$ & $3.51 \pm 1.45$ \\
\hline 3. It was difficult to arrange a date and time of my visit. & $1.26 \pm 0.693$ & $2.4 \pm 1.435$ \\
\hline 4. I could make the dental visit when I thought it was necessary. & $4.54 \pm 0.96$ & $4.29 \pm 1.243$ \\
\hline 5. The waiting room was attractive. & $4.44 \pm 1.017$ & $4.43 \pm 0.811$ \\
\hline 6. I was not kept waiting long at my last visit. & $4.29 \pm 1.125$ & $3.77 \pm 1.259$ \\
\hline 7. The dental clinic had anything needed for my dental care. & $4.82 \pm 0.703$ & $4.91 \pm 0.288$ \\
\hline 8. The dental clinic was modern. & $4.74 \pm 0.637$ & $4.69 \pm 0.542$ \\
\hline 9. The clinic staff was kind to me. & $4.88 \pm 0.615$ & $4.88 \pm 0.611$ \\
\hline 10. The professional I saw was indifferent towards me. & $1.23 \pm 0.84$ & $1.39 \pm 1.031$ \\
\hline 11. I saw the professional I wanted to. & $4.92 \pm 0.398$ & $4.55 \pm 1.052$ \\
\hline 12. I see the same professional every time. & $4.84 \pm 0.551$ & $4.31 \pm 1.105$ \\
\hline 13. The professional I saw explained thoroughly what treatment was needed. & $4.94 \pm 0.232$ & $4.86 \pm 0.569$ \\
\hline 14. The dental professional explained any patient costs. & $4.39 \pm 1.297$ & $4.45 \pm 1.145$ \\
\hline 15. The dental professional could have been more thorough examining me. & $1.3 \pm 0.834$ & $1.8 \pm 1.33$ \\
\hline 16. The dental professional answered my questions. & $4.89 \pm 0.442$ & $4.84 \pm 0.583$ \\
\hline 17. I would like to have had more explanation of my treatment plan. & $1.64 \pm 1.136$ & $1.77 \pm 1.262$ \\
\hline 18. The dental professional avoided expensive treatment plans. & $3.32 \pm 1.551$ & $3.19 \pm 1.396$ \\
\hline 19. I am satisfied with the dental care I received. & $4.83 \pm 0.56$ & $4.78 \pm 0.503$ \\
\hline 20. I received more dental care than I had to. & $3.99 \pm 1.412$ & $3.53 \pm 1.402$ \\
\hline 21. There were more dental problems that were not treated. & $1.48 \pm 0.983$ & $1.53 \pm 1.09$ \\
\hline 22. The dental care I received was painful. & $2.13 \pm 1.385$ & $2.49 \pm 1.477$ \\
\hline 23. The dental professional explained what was being done during the treatment. & $4.55 \pm 0.797$ & $4.43 \pm 0.775$ \\
\hline 24. The dental care gave solution to my dental problems. & $4.68 \pm 0.647$ & $4.76 \pm 0.427$ \\
\hline 25. The dental care I received did not improve my quality of life. & $4.84 \pm 0.477$ & $4.81 \pm 0.483$ \\
\hline 26. It took longer than I expected before my dental problems showed improvement. & $2.11 \pm 1.394$ & $2.35 \pm 1.386$ \\
\hline 27. My dental care cost me more than I could afford. & $2.28 \pm 1.431$ & $2.45 \pm 1.273$ \\
\hline 28. I believe that I received good dental care. & $4.84 \pm 0.39$ & $4.78 \pm 0.468$ \\
\hline 29. There are things in the clinic that could have been better. & $1.77 \pm 1.149$ & $1.65 \pm 0.983$ \\
\hline 30. My dentist gave me useful advice about my teeth and gums. & $4.77 \pm 0.605$ & $4.74 \pm 0.676$ \\
\hline 31. I feel protected against possible dental problems. & $4.8 \pm 0.51$ & 5 \\
\hline
\end{tabular}

The main difference found was the reason for choosing each clinic. The majority of participants in certified areas declared that they made their choice due to the certification, while the next most popular answer was the recommendation from others. On the other hand, the majority of participants chose the non-certified areas due to their dentist's specialization. A difference was also found in the reason of visit, where in the case of certified, the main reason was recall maintenance, whereas in uncertified the main reason was total rehabilitation of their mouth. The greater number of participants submitted for recall at certified clinics may be partly justified by the fact that in both clinics there is a periodontist, a specialty based mainly on the maintenance of the cured incidents.

The analysis of the questionnaire's general questions showed that in certified dental clinics the average number of days between the telephone communication and the final date of the appointment was $3.89 \pm 2.98$, while in non-certified the time interval was $5.86 \pm 4.36$ days. This difference is probably due to the fact that certified areas employ more staff and thus can serve a larger number of patients per day. In addition, they also have specialties such as endodontics and periodontics in which no external partner is involved, as opposed to the specialty of prosthetics and restorative dentistry. Instead, waiting time was longer in the case of certified clinics. 
Regarding the analysis of the main part of the questionnaire, the overall picture was that the satisfaction index from the two categories ranges to the same level without any major deviations. Indicatively, $89 \%$ of patients of the non-certified dental clinics were fully satisfied with the dental care they received, while the corresponding rate in the certified areas was $91 \%$. A reason that can explain this is the different dental education that exists in Greece. More specifically, the greek patient wants to have a more personal relationship with his dentist, not just solve his dental problem. Thus, their satisfaction depends to a large extent on their interpersonal relationship along with the quality of the dental care services. ${ }^{[15]}$

If a further analysis of the results of the questionnaire was made, there was a greater difficulty in making an appointment on the certified areas, which can be explained by the fact that many patients who come for total mouth rehabilitation should combine more than one dental specialties. One additional difference found in the questions was the fact that patients in certified dental clinics did not see the same dentist or the one they would like to see each time. The reason for this difference is the existence of many different specialties and therefore dentists, which sometimes create confusion among patients about who is responsible for the problem of their oral cavity. Similarly, the time of completion of their treatment plans in certified dental practices was increased, as patients who come to one of the certified clinics for total mouth rehabilitation, given that there are all specialties, start and complete their treatment plan in the same place as in the non-certified places patients complete the work of each specialty and continue to the next one.

At the points where the greatest division is found, both among the participants in the same category of clinics and among the participants in the two categories were the questions concerning the financial part. These questions did not have a clear majority in favor of a response, which can be justified by the fact that the perception of the objective value of each dental treatment varies from person to person.

Regarding the relation of demographic characteristics of patients to their satisfaction, no statically significant relationship was found, with the exception of the level of education of patients in certified dental clinics. This finding is opposed to that of other papers, where the higher the level of education, the less is the satisfaction. ${ }^{[14,16,17]}$ Differences also appear between these investigations, since the work of Ali and Lee et al. ${ }^{[14,16]}$ also found a statistically significant difference between sex and satisfaction, where women appear more satisfied, as well as age where the younger appear more pleased, while Khan's work has found no correlation. ${ }^{[17]}$

Completing the discussion of the results of the questionnaire, despite some fluctuations in other satisfaction questions, there is an absolute agreement of the participants of the certified dental clinics about the safety they feel about potential future dental problems.

The point to be specifically mentioned is the limitation of this study, which was the small number of sample that could be collected by certified private dental clinics due to their small number (two in the whole of Greece at this time) compared to the sample that can be collected from non-certified. Nevertheless, the sample was collected by both these clinics to make the results as accurate as possible.

The present study shows the current trend in patient satisfaction in the two categories of dental practice and enables individual managers to improve their image by identifying their weaknesses. In addition, it is the trigger for further study and comparison of results between different countries.

\section{ACKNOWLEDGEMENTS}

The contributions of staff and owners of the dental clinics who participated in data collection for this study are acknowledged.

\section{CONFLicts OF INTEREST Disclosure}

The authors declare no conflicts of interest.

\section{REFERENCES}

[1] Hescot P. The New Definition of Oral Health and Relationship between Oral Health and Quality of Life. Chin J Dent Res. 2017; 20(4): 189-192.

[2] Petersen PE. The World Oral Health Report 2003: continuous improvement of oral health in the 21 st century-the approach of the WHO Global Oral Health Programme Community Dent Oral Epidemiol. 2003; 31(1): 3-23. PMid:15015736. https : //doi .org/10 .1046/j . .2003. com122.x

[3] Tozan Y, Ompad DC. Complexicity and dynamism from an ur- ban health perspective: a rationale for a system dynamics approach. J Urban Health. 2015; 92(3): 490-501. PMid:25952137. https://doi.org/10.1007/s11524-015-9963-2

[4] Baummer-Carr A, Nicolau D. The challenges of patient satisfaction: influencing factors and the patient - provider relationship in the United States. Expert Rev Anti Infect Ther. 2017; 15(10): 955962. PMid:28893115. https://doi.org/10.1080/14787210.2 017.1378097

[5] Donabedian A. The Criteria and Standards of Quality. Journal of Ambulatory Care Management 1983; 6(2): 80-87. https://doi. 
org/10.1097/00004479-198305000-00015

[6] Tickle M, O' Malley L, Brocklehurst P, et al. A national survey of the public's views on quality in dental care. British Dental Journal. 2015 219(3): 1. PMid:26271885. https://doi.org/10.1038/sj.bdj .2015 .595

[7] Bahadori M, Raadabadi M, Ravangard R, et al. Factors affecting dental service quality. International Journal of Health Care Quality Assurance. 2015; 28(7): 678-689. PMid:26241090. https: //doi.org/10.1108/IJHCQA-12-2014-0112

[8] Righolt A, Sidorenkov G, Faggion C, et al. Quality measures for dental care: A systematic review. Community Dentistry and Oral Epidemiology. 2018; 47(1): 12-23. PMid:30375669. https ://doi . org/10.1111/cdoe.12429

[9] Lewney J. Quality measures for dental care: A systematic review. Evidence-Based Dentistry. 2019; 20(3): 79-80. PMid:31562407. https ://doi.org/10.1038/s41432-019-0048-z

[10] European Committee for Standardization. (2016). [online] Available from: http: //standards.cen.eu/dyn/www/f ? $p=204 \% 3 \mathrm{~A} 1$ $10 \% 3 \mathrm{A0} \% 3 \mathrm{~A} \% 3 \mathrm{~A} \% 3 \mathrm{~A} \% 3 \mathrm{AFSP}$ _PROJECT $\% 2 \mathrm{CFSP}$ _ORG_ID $\% 3 \mathrm{~A} 347$ $36 \% 2$ C622707\&Cs =1C9C7FAAC1E3E87D55B9C29F85F4CFC10 [Accessed 12 Mar. 2019].

[11] Lobo Prabhu K, Cleghorn M, Elnahas A, et al. Is quality important to our patients? The relationship between surgical outcomes and patient satisfaction. BMJ Qual Saf. 2018; 27(1): 48-52. PMid:29101291. https://doi.org/10.1136/bmjqs-2017-007071

[12] Lloyd H, Jenkinson C, Hadi M, et al. Patient reports of the outcomes of treatment: a structured review of approaches. Health Qual Life Outcomes. 2014; 12: 5. PMid:24422873. https ://doi .org/10.1 186/1477-7525-12-5

[13] Stewart JF, Spencer AJ. Dental Satisfaction Survey 2002. AIHW cat no. DEN 141. Adelaide: AIHW Dental Statistics and Research Unit. 2005.

[14] Lee K, Chen C, Huang S, et al. Patient satisfaction with the quality of dental treatment provided by interns. Journal of Dental Sciences. 2013; 8: 177-183. https://doi.org/10.1016/j.jds.2012.05. 015

[15] Dimitriadis D, Konstantinidis R, Sarafidou G, et al. Dentist - patient relationship. Perceptions and attitudes of private dental patients in an Athens municipality. Stomatologia. 2008; 65(2): 46-54.

[16] Ali DA. Patient satisfaction in Dental Healthcare Centers. European Journal of Dentistry. 2016; 10(3): 309-314. PMid:27403045. https://doi.org/10.4103/1305-7456.184147

[17] Khan A, Siddiqui A, Mohsin S, et al. Sociodemographic Characteristics as Predictors of Satisfaction in Public and Private Dental Clinics. Pakistan Journal of Medical Sciences. 2018; 34(5): 1152 1157. PMid:30344567. https : //doi .org/10.12669/pjms . 345 . 15519 